\title{
Gonads and Singing Play Separate, Additive Roles in New Neuron Recruitment in Adult Canary Brain
}

\author{
Benjamín Alvarez-Borda and Fernando Nottebohm \\ The Rockefeller University Field Research Center, Millbrook, New York 12545
}

New neurons are constantly added to the high vocal center (HVC) of adult male canaries, Serinus canaria. Singing and testosterone ( $\mathrm{T}$ ) are known to promote this addition, but it is not known whether either variable can act on its own and what is their effect when acting together. We studied this question by castrating adult male canaries in late summer and quantifying their song in early fall. Intact birds served as controls. A $5 \mathrm{~d}$ systemic treatment of two daily injections of the cell birth marker ${ }^{3} \mathrm{H}$-thymidine started $10 \mathrm{~d}$ after surgery. Twenty days after the first ${ }^{3} \mathrm{H}$-thymidine injection and for a period of 1 month, we quantified the singing of all birds, which were then killed. Amount of singing, syllable diversity, and song stability were

Canaries (Serinus canaria) are seasonal breeders that learn their song by reference to auditory information (Marler and Waser, 1977). Song is learned for the first time during the months preceding sexual maturity and can be modified on successive years. Most of the yearly modifications occur at the end of summer and in early fall, when blood testosterone (T) levels are low (Nottebohm et al., 1986, 1987). T has access to various song nuclei, where it or its metabolites are concentrated, (Arnold et al., 1976; Arnold, 1980; Balthazart et al., 1992; Gahr and Metzdorf, 1997) and there, presumably, exerts an effect on song. Three of these nuclei, high vocal center (HVC), robust nucleus of the archistriatum (RA), and the tracheosyringeal part of the hypoglossal nucleus (nXIIts) constitute the backbone of the descending pathway that controls the production of learned song (see Fig. 1A) (Nottebohm et al., 1976); a fourth nucleus, Area X, receives a strong projection from the HVC. Area X is necessary for song learning but not for the production of learned song (Bottjer et al., 1984; Scharff and Nottebohm, 1991).

New neurons are constantly added to the HVC of adult songbirds (Goldman and Nottebohm, 1983; Kirn et al., 1994). The work we report here counts the number of new neurons 50-55 d after injection of a birth date marker. Because our protocol did not discriminate between the contributions of new neuron production and new neuron survival, we use the term, "recruitment," which includes the contributions of both variables. Earlier studies showed that the survival of new HVC neurons can be influenced by testosterone and by singing. For example, female canaries that

Received Feb. 11, 2002; revised June 10, 2002; accepted July 1, 2002.

This work was supported by National Institutes of Health Grant MHI8343, the Mary Flagler Cary Charitable Trust, and generous support from Mr. Howard Phipps. We thank Daun Jackson, Sharon Seppe, and Helen Ecklund for their help in taking care of the canaries used in this study and Bhagwatti Haripal for help with histology.

Correspondence should be addressed to Benjamin Alvarez-Borda, 1230 York Avenue, Box 351, New York, NY 10021. E-mail: alvareb@mail.rockefeller.edu. Copyright (C) 2002 Society for Neuroscience $0270-6474 / 02 / 228684-07 \$ 15.00 / 0$ similar in intacts and castrates. When castrates and intacts that sang comparable amounts were compared, the number of ${ }^{3} \mathrm{H}$-labeled HVC neurons was 2.6 times higher in intacts than in castrates. In castrates with plasma $T$ levels that were undetectable, the mean amount of singing was positively related to the number of new neurons. We suggest that singing and gonadal factors promote, separately, the recruitment of new neurons and that when they exert this effect together they do so in an additive manner.

Key words: songbirds; canary; testosterone; singing; neurogenesis; new neurons; HVC normally sing little, sing a lot more when treated with testosterone (Leonard, 1939; Shoemaker, 1939; Baldwin et al., 1940; Herrick and Harris, 1957; Nottebohm, 1980), and in such birds there is an increase in the number of new neurons present in the HVC (Rasika et al., 1994). Conversely, survival of new HVC neurons is depressed in adult males that are prevented from singing (Li et al., 2000); conceivably, blood testosterone levels in these birds are depressed too. Because of the intimate relation between testosterone and singing, it is not clear at this time whether each of these two variables can promote neuronal recruitment on its own. That is one of the research questions addressed here.

Our strategy for separating the influence of testosterone and singing on new neuron recruitment was based on the observation that adult male canaries sing a lot in late summer and early fall, when blood testosterone levels are very low (Nottebohm et al., 1987). We speculated that at that time the amount of singing is not regulated by gonadal hormones. With this background in mind, we set out to test three questions. (1) Is the amount of singing and the quality of song in the fall similar in intact and castrate adult male canaries? (2) Is the recruitment of new HVC neurons similar in intacts and castrates that produce similar amounts of song? (3) Is new neuron recruitment correlated with the amount of singing in castrates? We felt that answers to these questions would help us understand to what extent singing and gonadal hormones contribute to the recruitment of new HVC neurons and, more broadly, help us understand the interaction of variables that promote neuron addition and replacement in adult brain.

\section{MATERIALS AND METHODS}

Animals. We used 24 16-month-old male Waterslager canaries (sexual maturity occurs in our colony at $\sim 8-10$ months) from our close-bred colony at the Rockefeller University Field Research Center. Animals were housed under New York State photoperiod. At the beginning of the study lights were turned on at 7 A.M. and off at 7 P.M. At the end, lights were turned on by 7:15 A.M. and off by 5 P.M.). Throughout the study 
food and water were available ad libitum. All protocols using live birds were approved by the Animal Care and Use Committee at Rockefeller University and followed National Institutes of Health guidelines for laboratory animal welfare. The experiments described were performed during the fall of 1998 and 1999.

Treatment protocols. Eighteen birds were castrated in late September and allowed $10 \mathrm{~d}$ to recover. For the next $5 \mathrm{~d}$, birds were given two daily injections of ${ }^{3} \mathrm{H}$-thymidine $(2.5 \mu \mathrm{Ci}$ per gram of body weight; New England Nuclear) at $12 \mathrm{hr}$ intervals. Starting on day 15 after the last injection, the amount of singing was scored for 1 month. Ten of the 18 birds were then given bilateral injections of the retrograde tracer fluorogold (FG) into the RA and killed $5 \mathrm{~d}$ later under deep anesthesia by intracardiac perfusion with $3 \%$ paraformaldehyde (Fig. 1B). Six controls were treated the same as the castrates but their gonads remained intact.

Blood was drawn from the birds in this study by wing vein puncture $2 \mathrm{~d}$ before castration and 8,27 , and $61 \mathrm{~d}$ after castration. For each sample, $\sim 200 \mu \mathrm{l}$ was obtained, and this did not appear to affect the animals in an obvious way; for example, there was no subsequent weight loss. The samples were centrif uged at $5000 \mathrm{rpm}$ for $10 \mathrm{~min}$, after which serum was collected and stored at $-70^{\circ} \mathrm{C}$ until it was assayed for testosterone content using the coat-A-count steroid detection assay (DPC). In this assay, $50 \mu \mathrm{l}$ of the blood sample are mixed with $1 \mathrm{ml}$ of a standard concentration of ${ }^{125} \mathrm{I}$-Testosterone and placed in a plastic tube coated with anti-Testosterone antibody at two dilutions. After a $3 \mathrm{hr}$ incubation at $37^{\circ} \mathrm{C}$, the samples were decanted and allowed to drain for $3 \mathrm{~min}$. The amount of radioactive label was then determined by comparing the values obtained for the samples with a standard dilution curve of ${ }^{125} \mathrm{I}-$ Testosterone. Samples were tested as duplicates to control for assay variability; the results were averaged for each sample. Birds with levels of circulating testosterone $>0.05 \mathrm{ng} / \mathrm{ml}$, which is the detection sensitivity of this assay, were removed from the study. Furthermore, after the birds had been killed, we verified that castrates had no gonadal regrowth and that intact birds did in fact have testes.

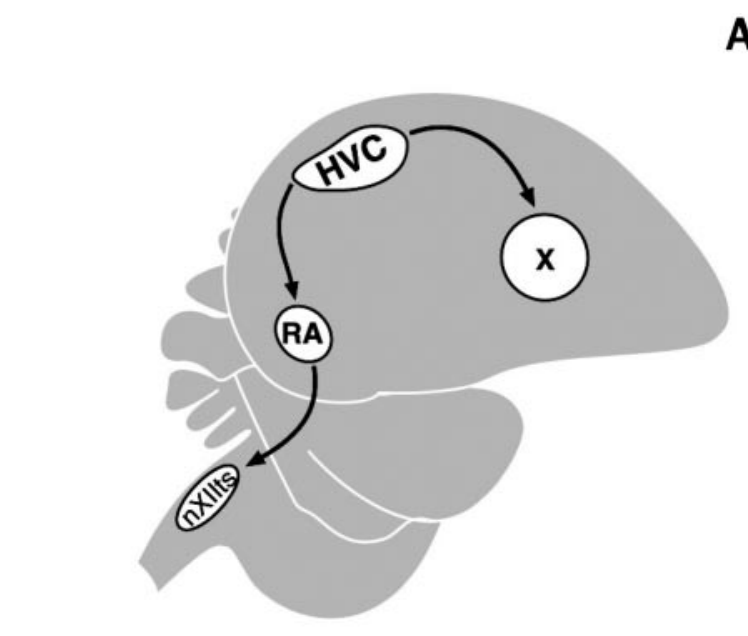

A

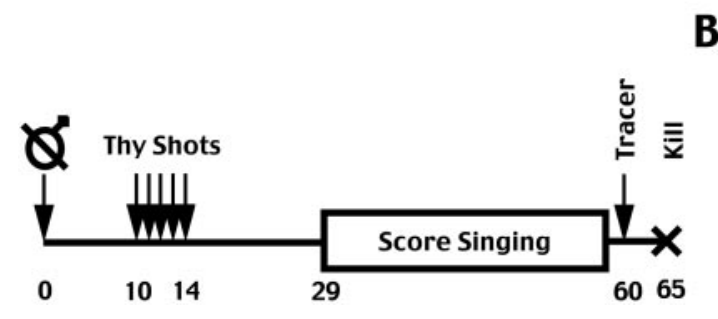

Figure 1. A, Sagittal view of the canary brain with the relative positions of HVC, RA, Area X, and nXIIts. Black arrows show the direction of projections between these nuclei. $B$, Experimental protocol used in this study. Birds were castrated on day 0 (crossed male symbol) and received twice-daily injections of ${ }^{3} \mathrm{H}$-thymidine for $5 \mathrm{~d}$ (days 10-14) and an injection of fluorogold tracer into RA on day 59. Amount of singing was scored during the month from day 29 to day 59 after castration. The birds were killed on day 65 .
Surgery. Canaries were anesthetized by an intramuscular injection of Nembutal (pentobarbital, $25 \mathrm{mg} / \mathrm{kg}$ body weight). Eighteen males were castrated by removing the testes by suction through a small incision between the two most caudal ribs. The stump was cauterized, and the wound was closed with Collodion (Fisher). One week after castration, all of these birds had undetectable blood testosterone levels. A second operation was performed on 10 of the 18 castrates $5 \mathrm{~d}$ before the animals were killed. In this case, after being anesthetized as described above, the birds were placed in a stereotaxic apparatus, and the skin over the skull was opened. Stereotaxic coordinates were obtained from our canary atlas (Stokes et al., 1974) to deliver four injections of FG. FG injections (10-20 $\mathrm{nl}$ each of $2.5 \% \mathrm{FG}$ in $0.9 \%$ saline) were aimed at the RA at the following stereotaxic coordinates: posterior 1.5 and 1.9 ; lateral 2.5 ; depth 2.5 and 2.3. To keep the injection tracts away from the HVC, the pipette was inserted caudal to the $\mathrm{HVC}$ at a $9^{\circ}$ angle in the anteroposterior plane.

Amount of singing. Birds were housed individually in cages set side by side so that all birds were in visual and auditory contact with each other. The amount of singing was scored by direct observation. A song was defined by the onset of singing after a period of silence and counted as a single song for however long the bird continued to sing uninterruptedly. The amount of singing was scored during $2 \mathrm{hr}$ periods at variable times during the day. Each bird was scored for at least $10 \mathrm{hr}$ every week. Mean song duration was calculated by randomly selecting six birds from the castrated group and six intacts; the song of each of these birds was recorded for $45 \mathrm{~min}$ on magnetic tape sometime during their last $10 \mathrm{~d}$ of life. We then divided the total amount of singing time (editing out the silent intervals between songs) by the number of songs produced.

Quality and diversity of song. Goldwave software was used to digitize the recorded song and view it spectrographically. The recorded songs of 9 of the above 12 birds ( 4 intacts and 5 castrates) were of sufficiently high quality (no interfering background) to be analyzed for syllable diversity and stability. For this we used for each bird a sample of 30-50 sec from the above recordings, selecting pieces of very good acoustic quality. These samples of song were then printed as sonograms, and for each bird we counted the number of syllable types present in that sample. A "syllable type" is a sound that in its visual representation is easily recognized as different from others. Syllable recognition is relatively easy in canaries because a same syllable is repeated several to many times, forming a phrase (see Fig. 2). In addition, repetitions of a same syllable were inspected visually to asses their variability. We used a scale of 1-5 in which 1 stood for the most variable rendering, as found in the plastic song of 3- to 4-month-old juveniles (Nottebohm et al., 1986), and 5 stood for the highly stereotyped repetitions found in adult males in breeding condition. A recent publication makes the point that visual scores of relative similarity between sounds are comparable to more sophisticated, computer-based scores (Tchernichovski et al., 2000). The person that scored the song of different birds for syllable diversity and stability did not know the treatment group to which each bird belonged.

Histology. Brains were removed after perfusion and placed in 3\% paraformaldehyde for $2 \mathrm{~d}$. Each brain hemisphere was embedded separately in polyethylene glycol and sectioned sagittally into $6-\mu \mathrm{m}$-thick slices. Sections cut at $60 \mu \mathrm{m}$ intervals were mounted serially. One set of six of these sections was stained for $\mathrm{Hu}$ immunoreactivity as described previously (Li et al., 2000). Hu has been shown to be a reliable neuronal marker in canary brain (Barami et al., 1995). These sections were then treated for autoradiography with Kodak NTB2 nuclear track emulsion for 4 weeks and developed with D19 (Kodak) as described elsewhere (Alvarez-Buylla et al., 1988). A second set of six sections was prepared for autoradiography and subsequently stained with cresyl violet. Cresyl violet is a Nissl stain that highlights the very pale nucleoplasm of neurons while staining darkly their nucleolus. Our reason for using both cresyl staining and $\mathrm{Hu}$ immunoreactivity was to have two independent ways of establishing neuronal identity. FG fluorescence was visible in both our cresyl-and Hu-stained material and helped us identify new RAprojecting neurons $\left(\mathrm{FG}^{+}\right.$and ${ }^{3} \mathrm{H}^{+}$). Pyknotic (degenerating) cells, characterized by their small size, very dark staining, and lack of resolution between nucleus and cytoplasm, were readily identifiable in our cresylstained material. The mean diameter of neuronal nuclei was estimated from a sample of 20 randomly chosen neurons from each bird. A cell was considered ${ }^{3} \mathrm{H}$-labeled when 10 or more grains were overlying the nucleus $\left(>20 \times\right.$ background); the mean diameter of ${ }^{3} \mathrm{H}$-labeled neuronal nuclei was calculated from measurements on 40 of the cells per bird. To correct for nucleus splitting in ${ }^{3} \mathrm{H}$-labeled and unlabeled neurons, we used Konigsmark's correction factor (Konigsmark, 1970), which gave us 
a corrected estimate of the total number of ${ }^{3} \mathrm{H}$-labeled and unlabeled HVC neurons per bird.

All anatomical analysis was done using computer-assisted microscopy as described elsewhere (Alvarez-Buylla and Vicario, 1988; Clark et al., 1990). The person doing the analysis did not know the treatment group to which each bird belonged. HVC boundaries were mapped in the same sections using dark-field viewing for FG and light-field viewing for cresyl violet staining. Both approaches were used to calculate the area of the HVC in the sections sampled. The sum of these areas multiplied by section thickness and spacing between sections was used as an estimate of $\mathrm{HVC}$ volume. Estimates of cell numbers in the HVC were calculated by multiplying total HVC volume by the neuron density of the tissue sampled.

Comparison of left and right hemispheres revealed no systematic differences, so both sides were averaged. When fluorogold injections on one side were found to be off target, the data for that side were discarded.

Statistical analysis. Comparisons between groups were made using the Mann-Whitney test, because we could not be confident that the results for individuals within a group showed a normal distribution because of the relatively small group sizes. Values were considered to be significantly different if the probability of them occurring by chance was 0.05 or lower. Variance around the mean is presented as SE of the mean. Linear regression analysis was performed to establish a correlation between singing and new neuron recruitment. We report the coefficient of determination $\left(r^{2}\right)$ to assess the strength of the correlation and report $p$ values for the significance of the test.

\section{RESULTS}

\section{Similar amount of singing in intacts and castrates}

There was considerable variability in the number of songs per unit time produced by intacts and castrates. Castrates sang a mean of 35.7 songs per hour (range, $10-55$ songs). This mean was not very different from the average 40 songs per hour (range, 26-62 songs) produced by the intact birds $(p>0.05)$ (Fig. 2). In addition, there were no significant differences in the mean duration of song in the two groups, or even between members of the same group. Average song duration was similar in castrates and intacts $(8.4 \pm 2.1$ and $8.8 \mathrm{sec} \pm 1.4 \mathrm{sec}$, respectively; $p>0.05)$. The number of songs produced per hour was therefore a good measure of the amount of singing. The similarity in the amount of singing produced by intacts and castrates in the fall is in striking contrast to

0"00 2"00 $\quad$ 2"00 $\quad 4$ "

$11 \mathrm{KHz}$
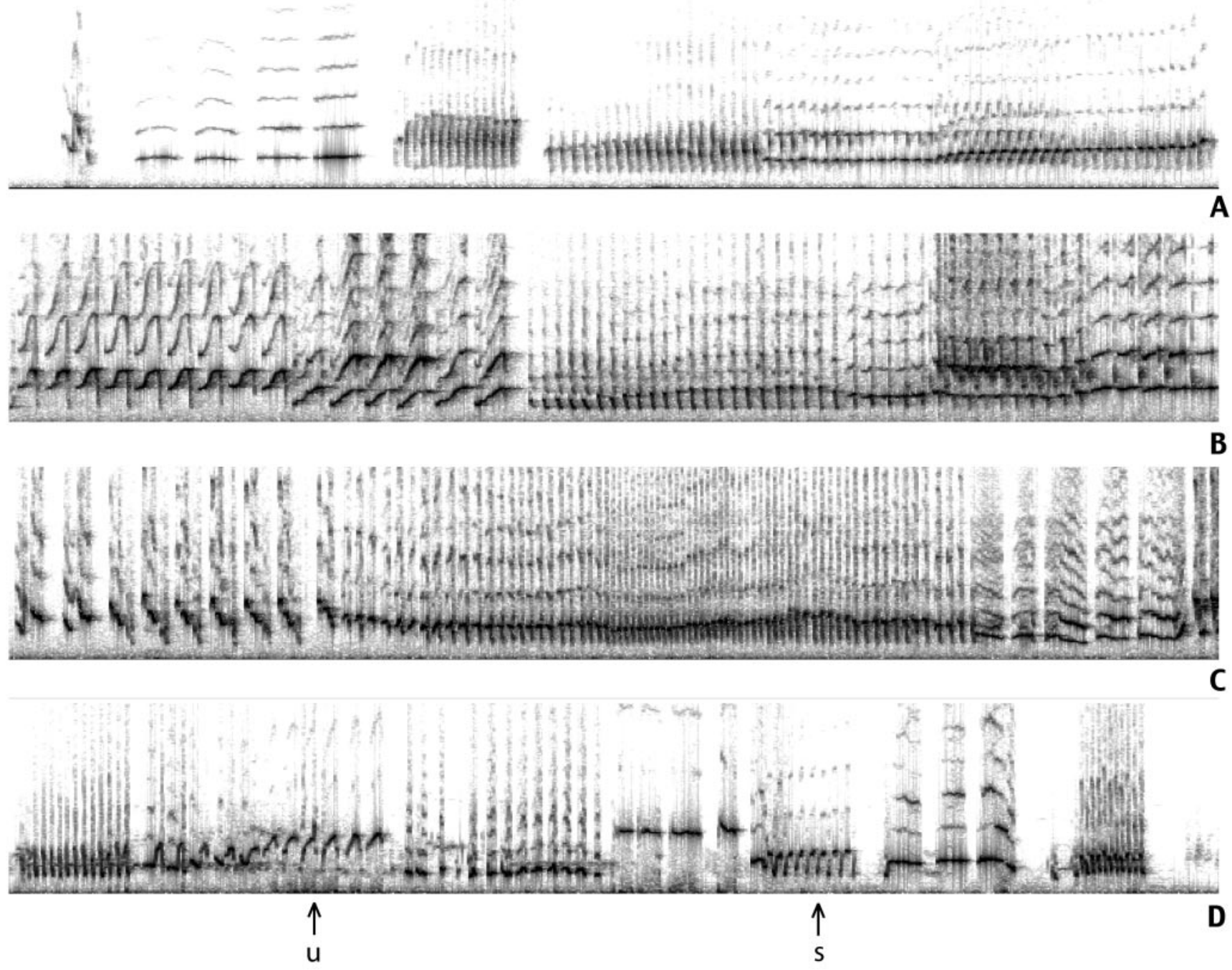

Figure 2. Samples ( $8 \mathrm{sec}$ each) of the songs of two intacts $(A, C)$ and two castrates $(B, D)$. The two top birds were chosen because their song was judged to be relatively stable (score of 4-4.5), whereas the two bottom ones were judged to be less stable (score of 3.5-4). The sounds that were displayed range from 0 to $10 \mathrm{kHz}$. Notice that a same bird $(D)$ can produce a same syllable in a relatively stable manner $(s)$, whereas other syllables are less stable $(u)$. 


\begin{tabular}{lcll}
\hline Table 1. Effect of castration on HVC volume & \\
& $\begin{array}{l}\text { Nuclear diameter } \\
\text { (in } \mu \mathrm{m})\end{array}$ & $\begin{array}{l}\text { Volume } \\
\left(\mathrm{mm}^{3}\right)\end{array}$ & $\begin{array}{l}\text { Pyknotic cells } \\
\text { (per HVC) }\end{array}$ \\
\hline Castrated & $6.12 \pm 0.54$ & $0.287 \pm 0.09$ & $19.2 \pm 4.7$ \\
Intact & $7.3 \pm 0.35$ & $0.362 \pm 0.084$ & $10.4 \pm 4.8$ \\
\hline
\end{tabular}

This table shows the nuclear diameter, in micrometers, of new HVC neurons of castrated and normal birds. Also shown are the volumes of $\mathrm{HVC}$ measured in $\mathrm{mm}^{3}$ and the total number of pyknotic cells found in each HVC.

singing behavior in the spring, when intact male canaries sing a lot and castrate canaries fall silent (Nottebohm, 1980).

\section{Similar syllable diversity and syllable stability in intacts and castrates}

The number of different syllables produced by intacts and castrates during the $30-50 \mathrm{sec}$ of song sampled ranged from 16 to 32 different syllable types, with complete overlap between intacts $(16,16,21$, and 28) and castrates $(16,20,23,30$, and 32). Similarly, stereotypy scores were very similar between the two groups, ranging from 3.5 to 4.5 , with complete overlap between the groups. This similarity in the song of castrates and intacts is well represented in Figure 2.

\section{Effect of castration on blood testosterone levels}

Castrates had a significant drop in circulating testosterone levels. Two days before castration, both groups had the same levels of testosterone $(p=0.8)$. Eight days after castration, circulating testosterone levels in the 18 castrates had plummeted below 0.05 $\mathrm{ng} / \mathrm{ml}$, and they remained at those levels for the rest of the experiment. The differences with the intact group also remained highly significant at longer postoperative intervals $(27 \mathrm{~d}, p<$ $0.001 ; 61 \mathrm{~d}, p<0.001)$. We found traces of testicular tissue in two of the castrate birds with measurable $\mathrm{T}$ levels.

\section{Effect of castration on HVC volume}

Castration induced a significant decrease in the mean volume of the HVC. The volume of the HVC, as determined by FG backfills, went down from $0.362 \mathrm{~mm}^{3}$ in intact birds to $0.287 \mathrm{~mm}^{3}$ in castrates $(p<0.001)$. A similar decrease was seen when the borders of the HVC were determined by cresyl violet staining, and no significant differences were found between the two methods $(p=0.63)$ (Table 1$)$.

\section{Effect of castration on the nuclear diameter and number of new HVC neurons and number of pyknotic cells}

As shown in Table 1, the mean nuclear diameter of unlabeled HVC neurons was $7.3 \mu \mathrm{m}$ in intacts and $6.1 \mu \mathrm{m}$ in castrates, a difference that was significant $(p<0.05)$. This reduction is likely to be at least partly responsible for the observed reduction in HVC volume.

On the other hand, estimates of the total number of neurons did not vary much between intact and castrate birds (41,000 and 37,212 neurons, respectively; $p=0.06$ ). There was also a nonsignificant reduction in the proportion of RA projecting cells, such that $53 \%$ of neurons projected to RA in normal birds compared with $49 \%$ in castrates $(p=0.074)$ (Fig. 3). The differences in estimates of total neuron number are very close to being significant; it is possible that an effect is being masked by the relatively small sample sizes used and by the high sample variability found among castrates.

We also found differences in the numbers of pyknotic cells. An

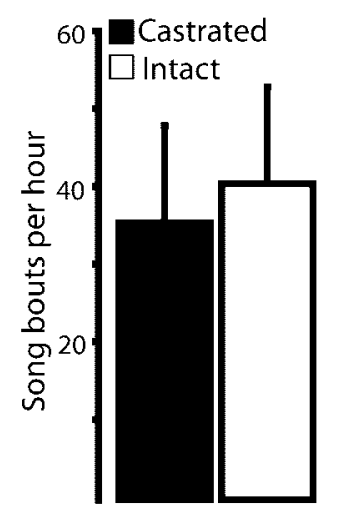

A

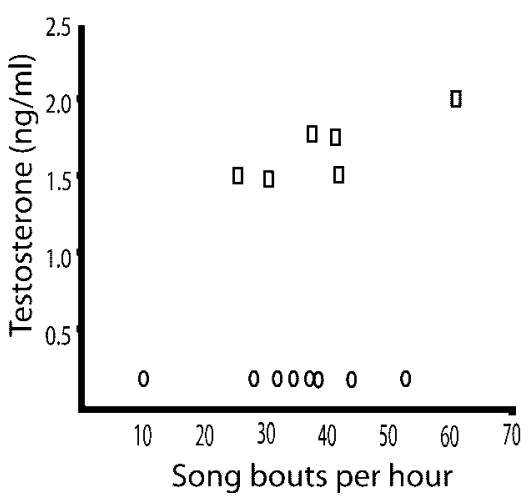

C

\begin{tabular}{|ccc|}
\hline \multicolumn{3}{c|}{ Circulating Testosterone $(\mathrm{ng} / \mathrm{ml})$} \\
\hline Group & Before Surgery & After surgery \\
Castrated & $1.675 \pm 0.08$ & $0.05 \pm 0.0$ \\
Intact & $1.72 \pm 0.12$ & $1.69 \pm 0.05$ \\
\hline
\end{tabular}

Figure 3. A, Castration did not alter dramatically the amount of singing in the fall. The mean number of songs per hour was similar in intacts and castrates. $B$, Castrates $(\bigcirc)$ and intacts $(\square)$ differed markedly in blood $\mathrm{T}$ levels, but the number of songs produced per hour by birds in both groups showed broad overlap. Blood T levels, which were below detection in all castrates, are shown here at an arbitrary point between 0 and $0.5 \mathrm{ng} / \mathrm{ml}$. $C$, Intacts and castrates had similar levels of circulating $\mathrm{T}$ before gonadectomy was performed on the latter birds, but these levels differed markedly after castration.

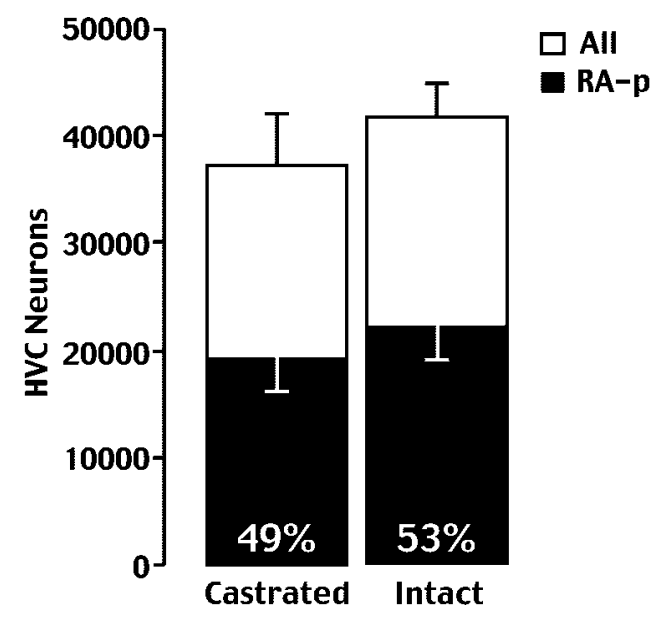

Figure 4. Estimated number of all neurons in the HVC (white bars) and neurons in the HVC that were backfilled with FG from RA (black bars). Both numbers, as well as the percentage of HVC cells that were backfilled from RA, were comparable in intact and castrated birds.

estimated average of 19.2 pyknotic cells occurred per HVC of castrates, and this number was significantly greater $(p<0.05)$ than the mean of 10.4 pyknotic cells per HVC of normal canaries (Table 1).

We found a dramatic reduction in the estimated total number of ${ }^{3} \mathrm{H}$-labeled neurons in the HVC of castrates $(250.3 \pm 49.2 ; n=$ 18), compared with that in intacts $(597 \pm 38.6 ; n=6)$ (Fig. 4). This is a significant $(p<0.01) 2.17$-fold reduction in the per- 
centage of new HVC neurons per day of treatment, from $0.291 \%$ in intact birds to $0.134 \%$ in castrates. There was also a significant drop in the estimated number of new neurons that project to RA (intact 471.63 \pm 48.6 , castrates $107 \pm 69.3 ; p<0.01$ ), as well as in the ratio of new RA projecting neurons to total new neurons (intact 0.79 , castrate $0.44 ; p<0.01$ ).

Interestingly, the difference in number of new HVC neurons between castrates and intacts persisted even when we matched the results for the intacts with those of the six castrates that best resembled them in total amount of singing. When those two groups of six birds were compared, the number of ${ }^{3} \mathrm{H}$-labeled neurons was 2.6 times higher in the intacts than in the castrates.

\section{Number of new RA projecting neurons in castrates is correlated with amount of singing}

Despite the large decrease in ${ }^{3} \mathrm{H}$-labeled neuron numbers in castrated birds, we still found great variability between subjects. However, this variability was not random. There was a positive relation between the number of ${ }^{3} \mathrm{H}$-labeled neurons and amount of singing $\left(r^{2}=0.82 ; p<0.01\right)$. When we assigned the ${ }^{3} \mathrm{H}$-labeled neurons to one of two groups, those backfilled with FG and therefore presumed to project to RA and those not backfilled with FG, we found that the correlation with singing was weaker in the latter group $\left(r^{2}=0.447, p=0.0613\right.$ vs $r^{2}=0.900, p<0.01$, respectively) (Fig. 5).

To further confirm the results that we obtained with our cresyl violet-stained material, we did parallel counting of new neurons in the HVC in sections stained for $\mathrm{Hu}$ immunoreactivity. The results were comparable. For the 10 birds backfilled with fluorogold from RA, we found an average of 274.8 new neurons in cresyl-stained sections and 298.6 new neurons in Hu-labeled sections of the HVC $(p>0.05)$. Using $\mathrm{Hu}$ as the determinant of neuronal identity, we were able to reproduce the correlations found between amount of singing and new neurons in the HVC (Figs. 6, 7).

\section{DISCUSSION}

Our first question was the following: is the amount of singing produced by adult male canaries in the fall comparable in intacts

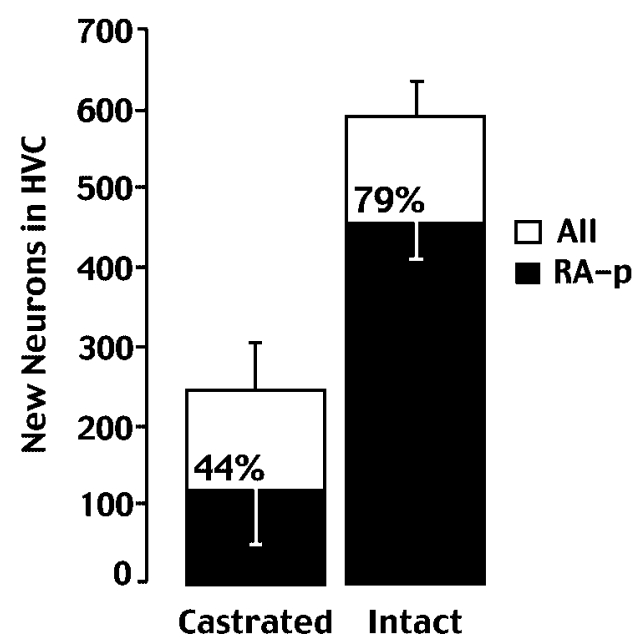

Figure 5. New neurons in the HVC of normal and castrated canaries. The number of total new HVC neurons (white bars) and new HVC neurons that were backfilled with FG from RA (black bars) was markedly smaller in the castrates, as was the percentage of all new cells that were backfilled from RA. and castrates? For our sample, the answer was yes. A MannWhitney comparison of singing in castrates and intacts failed to show a significant difference in amount of singing between groups. Furthermore, there were no marked differences between castrates and intacts in syllable diversity or syllable stability. These observations provided us with conditions favorable for trying to tease apart the extent to which singing and gonadal factors influence the number of new neurons present in the HVC.

Our second question was the following: is the recruitment of new HVC neurons similar in intacts and castrates that sing similar amounts of song? The answer to this question was no. Even when matched for amount of singing, the birds with the intact gonads had 2.6 times as many new neurons as the castrates. Clearly, amount of singing does not, by itself, fully predict the level of new neuron recruitment.

Our third question was as follows: is new neuron recruitment correlated with amount of singing in castrates? The answer was yes. The number of new HVC neurons in birds with gonads that had been removed was strongly related to the amount of singing. The number of new neurons in the birds that sang the most $(\sim 59$ songs per hour) was 1.87 times greater than in the birds that sang the least ( $\sim 11$ songs per hour), using the two extremes of our regression line as points of reference.

Our fourth observation was unexpected. Although castration had a strong effect on the number of new, FG-backfilled, RAprojecting HVC neurons (471 in intacts vs 107 in castrates), there was no such effect on the number of new HVC neurons that were not backfilled from RA (126 in intacts vs 143 in castrates). We infer from this that the survival of a subset of new HVC neurons is not affected by gonadal factors. Interestingly, this subset was also little influenced by singing. Existing evidence indicates that there are no other projection neurons added to the adult canary HVC. Possibly, the new neurons whose numbers are not affected by castration or singing are interneurons.

Taken together, our results indicate that both singing and gonadal factors have a positive effect, of similar magnitude, on the recruitment of new RA-projecting HVC neurons and that these two effects, when they occur together, are additive.

We will now have a closer look at the data and the interpretations. Castration was accompanied by a strong reduction in testosterone levels. Castration might have also reduced other gonadal factors released into the blood stream. Thus, although we are able to show the effect of castration on plasma testosterone levels, we cannot say that this was the only substance with altered blood concentration. Similarly, we cannot rule out the possibility that testosterone or other androgens are synthesized in the brain, where they could have an effect without appearing in the blood stream; birds that sang the most might have had greater synthesis of brain endogenous androgens than those that sang the least. Our experiments do not address this issue. In addition, there is the possibility that androgens of non-gonadal sources, such as the adrenals, affect behavior. For example, recent work in song sparrows has shown that levels of circulating dehydroepiandrosterone, a compound that we did not test for that is normally produced by testes as well as by the adrenal glands and can be metabolized into testosterone, are high in the fall when testosterone levels are low (Soma and Wingfield, 2001). Furthermore, it is interesting to note that studies on wild canaries caught in the fall have found much lower levels of circulating testosterone than in captive-bred canaries (Leitner et al., 2001). Because of the above uncertainties, we can only indicate that, on the basis of the data on hand, both 

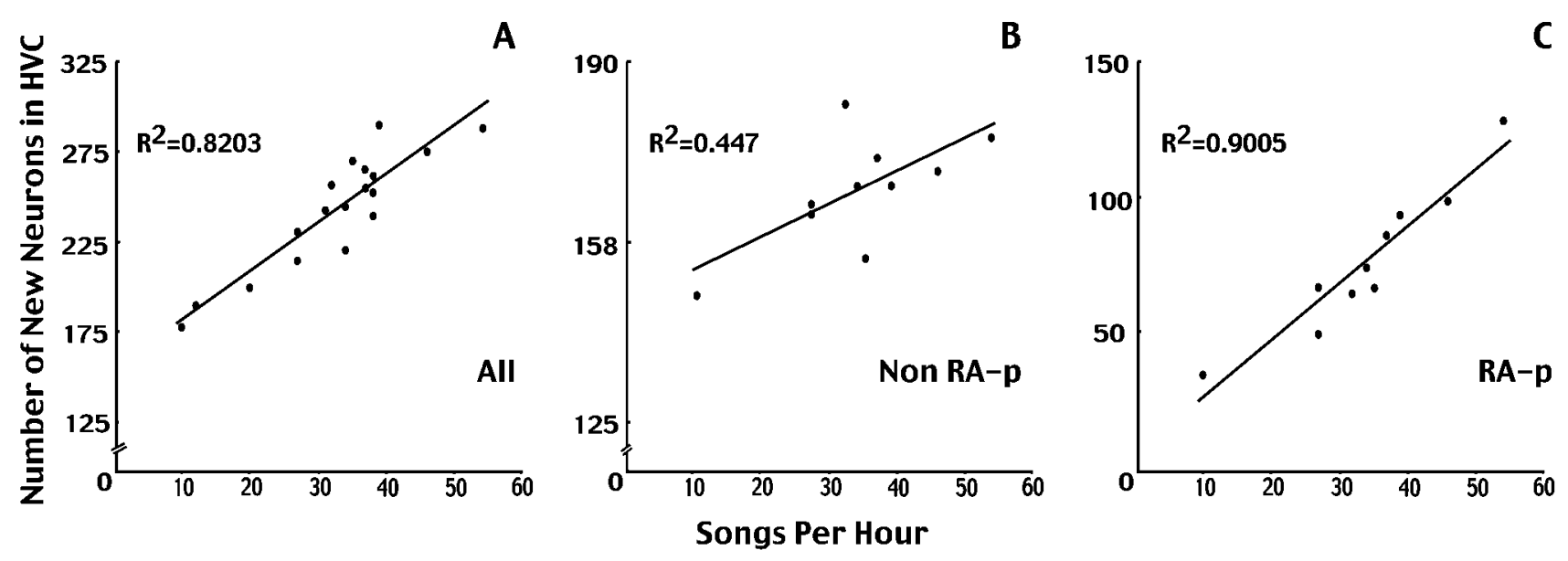

Figure 6. There was a positive correlation in our castrates between amount of singing (songs per hour) and number of ${ }^{3} \mathrm{H}-$ labeled $\mathrm{HVC}$ neurons per day of ${ }^{3} \mathrm{H}$-thymidine injection. Neuronal identity was established by the manner in which neuronal nuclei stained with cresyl violet. The three panels show the correlation between amount of singing; $A$, total number of ${ }^{3} \mathrm{H}$-labeled $\mathrm{HVC}$ neurons $(n=18)$; $B$, number of ${ }^{3} \mathrm{H}$-labeled $\mathrm{HVC}$ neurons that were not backfilled from RA (mostly interneurons?); $C$, number of ${ }^{3} \mathrm{H}$-labeled $\mathrm{HVC}$ neurons backfilled from RA (projection neurons). Ten of the 18 birds in $A$ received FG injections and are the ones shown in $B$ and $C$.
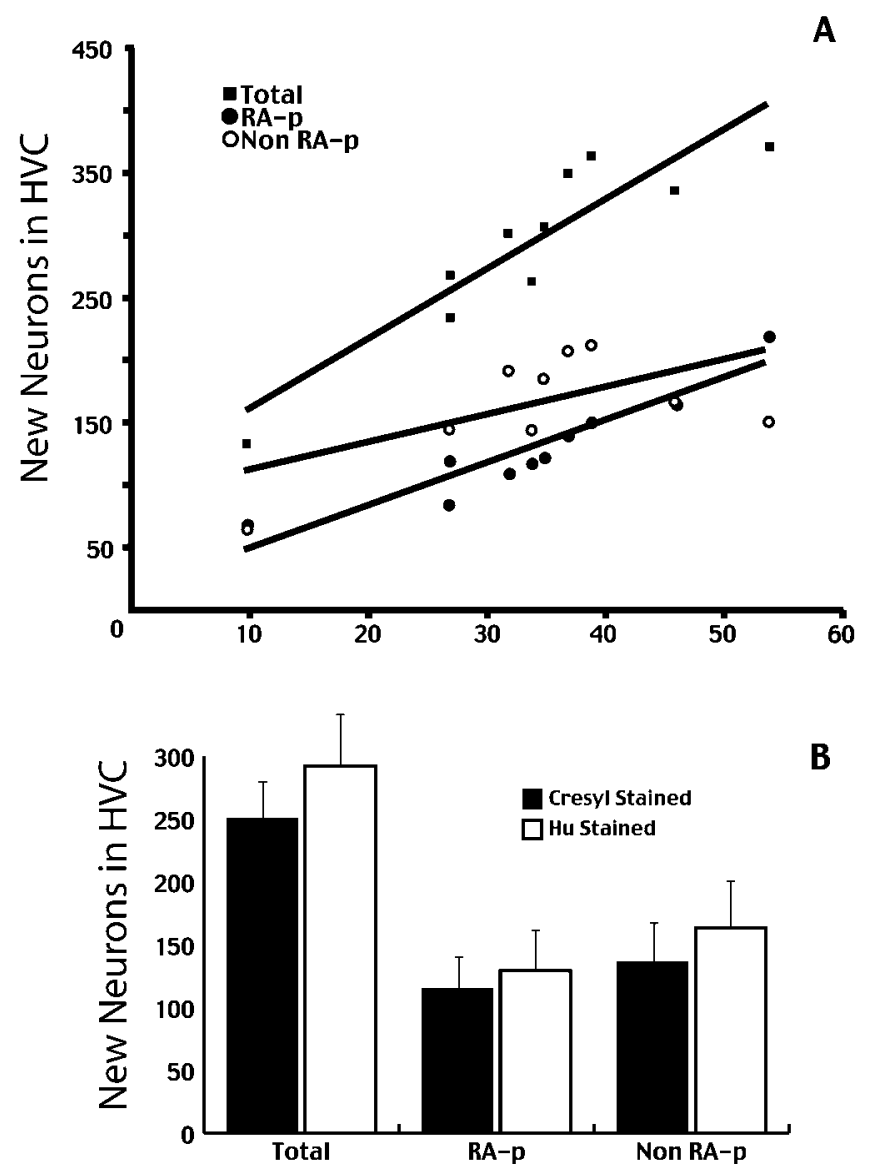

Figure 7. We obtained results similar to those shown in Figure 4 when Hu staining was used, in castrates, as the neuronal marker. $A$ shows the correlations between amount of singing and number of new neurons, number of new neurons backfilled from RA, and number of new neurons not backfilled from RA $\left(r^{2}=0.835, r^{2}=0.88, r^{2}=0.364\right.$, respectively). $B$ compares new neuron counts using cresyl or Hu staining as the marker of neuronal identity. Counts that used cresyl staining were lower than those that used $\mathrm{Hu}$, probably because the former excluded cells or fragments of cells with nuclei that were too small to ascertain neuronal identity. Despite this small discrepancy, counts that used either of the two ways to identify neurons revealed the same relation between new neuron numbers and singing. singing and gonadal factors seem to play a role in new neuron recruitment.

The effects of singing and testosterone or other gonadal factors on new neuron recruitment may be mediated by a common mechanism. Specifically, a rise in plasma testosterone levels, as when giving adult female canaries SILASTIC implants of testosterone, is accompanied by increased BDNF levels in the HVC. In addition, the recruitment of new HVC neurons that is enhanced in these same birds by testosterone is blocked by infusion of an anti-BDNF antibody into the HVC (Rasika et al., 1994, 1999). Likewise, higher levels of singing in adult male canaries are accompanied by a greater survival of new HVC neurons and by greater BDNF expression in the HVC (Li et al., 2000). Thus, both testosterone and singing may influence new neuron survival by tapping the same neurotrophin-mediated mechanism.

There is evidence from birds (Kirn et al., 1994; Barnea and Nottebohm, 1996; Scott et al., 2000) and mammals (Shors et al., 2001) that suggests that new neurons play a role in learning. Our results do not address this issue because we do not know whether the intact and castrate groups modified their song repertoire after our experiment started or to what extent they would retain this repertoire 2, 4, or 6 months later. To this extent, we do not know whether the 2.6-fold difference in number of new neurons that we observed between castrates and intacts producing comparable amounts of song had consequences on learning. However, we do know that before the birds in the two groups were killed, the quality and amount of their song were comparable.

Our results show that in canaries castration does not have a marked effect on the quality or quantity of fall song, although it dramatically reduces the recruitment of new HVC neurons. In these birds, new neuron recruitment is positively related to amount of singing. We infer that the effects of gonadal factors and singing are additive, both promoting a greater recruitment of new HVC neurons. The benefits of singing on survival are mostly reaped by a class of cell, the RA projecting neuron, thought to be involved in the production of learned song. We know from other work that these new neurons will then linger for at least another 8 months, until the next year's breeding season (Kirn et al., 1991). The significance of all of this on learning, if any, remains to be demonstrated. 


\section{REFERENCES}

Alvarez-Buylla A, Vicario DS (1988) Simple microcomputer system for mapping tissue sections with the light microscope. J Neurosci Methods 25:165-173.

Alvarez-Buylla A, Theelen M, Nottebohm F (1988) Birth of projection neurons in the higher vocal center of the canary forebrain before, during, and after song learning. Proc Natl Acad Sci USA 85:8722-8726.

Arnold AP (1980) Quantitative analysis of sex differences in hormone accumulation in the zebra finch brain: methodological and theoretical issues. J Comp Neurol 189:421-436.

Arnold AP, Nottebohm F, Pfaff DW (1976) Hormone concentrating cells in vocal control and other areas of the brain of the zebra finch (Poephila guttata). J Comp Neurol 165:487-511.

Baldwin FM, Goldin HS, Metfessel M (1940) Effects of testosterone propionate on female Roller canaries under complete song isolation. Proc Soc Exp Biol Med 44:373-375.

Balthazart J, Foidart A, Wilson EM, Ball GF (1992) Immunocytochemical localization of androgen receptors in the male songbird and quail brain. J Comp Neurol 317:407-420.

Barami K, Iversen K, Furneaux H, Goldman SA (1995) Hu protein as an early marker of neuronal phenotypic differentiation by subependymal zone cells of the adult songbird forebrain. J Neurobiol 28:82-101.

Barnea A, Nottebohm F (1996) Recruitment and replacement of hippocampal neurons in young and adult chickadees: an addition to the theory of hippocampal learning. Proc Natl Acad Sci USA 93:714-718.

Bottjer SW, Miesner EA, Arnold AP (1984) Forebrain lesions disrupt development but not maintenance of song in passerine birds. Science 224:901-903.

Clark SJ, Cynx J, Alvarez-Buylla A, O’Loughlin B, Nottebohm F (1990) On variables that affect estimates of the true sizes and densities of radioactively labeled cell nuclei. J Comp Neurol 301:114-122.

Gahr M, Metzdorf R (1997) Distribution and dynamics in the expression of androgen and estrogen receptors in vocal control systems of songbirds. Brain Res Bull 44:509-517.

Goldman SA, Nottebohm F (1983) Neuronal production, migration, and differentiation in a vocal control nucleus of the adult female canary brain. Proc Natl Acad Sci USA 80:2390-2394.

Herrick EH, Harris VO (1957) Singing female canaries. Science 125:1299-1300.

Kirn J, O'Loughlin B, Kasparian S, Nottebohm F (1994) Cell death and neuronal recruitment in the high vocal center of adult male canaries are temporally related to changes in song. Proc Natl Acad Sci USA 91:7844-7848.

Kirn JR, Alvarez-Buylla A, Nottebohm F (1991) Production and survival of projection neurons in a forebrain vocal center of adult male canaries. J Neurosci 11:1756-1762.

Konigsmark BW (1970) The counting of neurons. In: Contemporary research methods in neuroanatomy (Nauta W, Ebesson S, eds), pp 315-340. New York: Springer.

Leitner S, Voigt C, Garcia-Segura LM, Van't Hof T, Gahr M (2001) Seasonal activation and inactivation of song motor memories in wild canaries is not reflected in neuroanatomical changes of forebrain song areas. Horm Behav 40:160-168.

Leonard SL (1939) Induction of singing in female canaries by injections of male hormone. Proc Exp Biol 41:229-230.

Li XC, Jarvis ED, Alvarez-Borda B, Lim DA, Nottebohm F (2000) A relationship between behavior, neurotrophin expression, and new neuron survival. Proc Natl Acad Sci USA 97:8584-8589.

Marler P, Waser MS (1977) Role of auditory feedback in canary song development. J Comp Physiol Psychol 91:8-16.

Nottebohm F (1980) Testosterone triggers growth of brain vocal control nuclei in adult female canaries. Brain Res 189:429-436.

Nottebohm F, Stokes TM, Leonard CM (1976) Central control of song in the canary, Serinus canarius. J Comp Neurol 165:457-486.

Nottebohm F, Nottebohm ME, Crane L (1986) Developmental and seasonal changes in canary song and their relation to changes in the anatomy of song-control nuclei. Behav Neural Biol 46:445-471.

Nottebohm F, Nottebohm ME, Crane LA, Wingfield JC (1987) Seasonal changes in gonadal hormone levels of adult male canaries and their relation to song. Behav Neural Biol 47:197-211.

Rasika S, Nottebohm F, Alvarez-Buylla A (1994) Testosterone increases the recruitment and/or survival of new high vocal center neurons in adult female canaries. Proc Natl Acad Sci USA 91:7854-7858.

Rasika S, Alvarez-Buylla A, Nottebohm F (1999) BDNF mediates the effects of testosterone on the survival of new neurons in an adult brain. Neuron 22:53-62.

Scharff C, Nottebohm F (1991) A comparative study of the behavioral deficits following lesions of various parts of the zebra finch song system: implications for vocal learning. J Neurosci 11:2896-2913.

Scott LL, Nordeen EJ, Nordeen KW (2000) The relationship between rates of $\mathrm{HVc}$ neuron addition and vocal plasticity in adult songbirds. J Neurobiol 43:79-88.

Shoemaker HH (1939) Effect of testosterone propionate on the behavior of the female canary. Proc Exp Biol 41:229-230.

Shors TJ, Miesegaes G, Beylin A, Zhao M, Rydel T, Gould E (2001) Neurogenesis in the adult is involved in the formation of trace memories. Nature 410:372-376.

Soma KK, Wingfield JC (2001) Dehydroepiandrosterone in songbird plasma: seasonal regulation and relationship to territorial aggression. Gen Comp Endocrinol 123:144-155.

Tchernichovski O, Nottebohm F, Ho CE, Pesaran B, Mitra PP (2000) A procedure for an automated measurement of song similarity. Anim Behav 59:1167-1176. 